\title{
A CATHODE-FOLLOWER POWER AMPLIFIER*
}

Salvatore Giordano and Mario Puglisi Brookhaven National Laboratory Upton, New York 11973

\section{Sumarg}

In circular accelerators and particularly in storage rings it is essential that the total inpedance, as seen by the beam, be kept below some critical value. A model of the accelerating system vas built using a single-ended cathode-follower anplifier driving a ferrite-looded cavity. The oystem operated at $234.5 \mathrm{kBz}$ with a peak output voltage of $\pm 10 \mathrm{kV}$ on the gap. The dyomic output impedance, an measured on the gap, was < 15 ohms.

\section{Introduction}

Eigh intenaity beams in circular accelerators and torage rings require that the gap coupling impedance of the vacurum chmber and anociated equipment be very mall over a wide frequency range. For the cace of the accelerating cayity and $R F$ mplifier there are two wethods that can be used for lowering the inpedance: 1) shuating the cavity with a resistor and 2) uaing an amplifier with negative feedback. For the Colliding Beam Accelerator (CBA) it would be desirable to bave a gap coupling impedance of $15 \Omega$ per gap or less. With a peak gap voltage of $12 \mathrm{kV}$ it is obvious that resistive loading would require a prohibitive anouat of $\mathrm{BF}$ pover.

The use of an amplifier with negative feedback is the best choice from an economic point of view, but there are sowe technical problens that must be considered. There are three basic anplifier circuits: grounded cathode, grounded grid and grounded anode (cathode follower). The first two circuits have been extensively ueed in the past; both with and without feedback. The feedback loop for use with the above two circuite must, by the very anture of the circuits, contain two or ore phase lag elents; consequently, to insure stability, severe reatrictions must be placed on the gain bandwidth. It ohould als: be noted that by the very anture of the physically large components used, parasitic reactances asociated with these components will adversely affect the amplifier.

The big advantage of a cathode follower is that no external feedback network is required to achieve a feedback ratio of $\mathrm{Br} 1$. The disadvantage is that a cathode follower can becose unstable under certain. conditions when the load is reactive, but it will be shown that it can be easily stabilized with a damping reaistor and essentially not effect its bandwidth and low output impedance.

\section{Amplifier Considerations}

If we are to mintain a low dynamic output impedance over a wide frequency range it is important that the tube or tubes be conducting over the whole of the RF cycie; moreover, the concept of impedance impliea a linear circuit. The effect of bem loading will influence the election of both the amplifier circuit and operating conditions of the tubes to satisfy the above requirements.

It has bern shown that aplifiers with remonant loade can be operated in a nonlinear fashion (where

Work performed under the auspices of the U.S. Depart ment of Energs. the tube cuts off) and still effectively reduce beal loading effects. The concept of impedance becomes weaningless, but an effective, conservative desiga is posaible. This paper vill not deal with this concept or design; a wore detailed study of non linear beam loadiag effects vill be found in the Reference.

Fugh Pull vs. Single Ended

In addition to an output impedance of 15 ohm or less for each aplifier, the CDA amplifier wust weet the following requirenents: peak voltage $\pm 12 \mathrm{k} \nabla$ and a peak ( $I_{p}$ ) and average (Ia) beam eurrent of 40 amps and $B$ amp respectively (see Fig. 1). It should be noted that in order to mintsin a low output impedance the peak beaw current becone almost equal to the instantaneous dynaric tube current; therefore, the mplifier tube must be capable of conducting the peak beas current without going into saturation. For a push pull anplifier as one tube is being driven into saturation, it is also necesary to keep the second tube from being cut off.

The single ended amplifier to be described in this paper, that was constucted and tested, was $1 \mathrm{im}-$ ited to an output voltage of $\pm 10 \mathrm{kV}$. For economic reasons we used an existing power supply and filter capacitors, thich linited the system from operating above this level. We feel that operation of the amplifier at $\pm 12 \mathrm{kV}$ will be no different than what was observed at $\pm 10 \mathrm{k}$.

Let us consider the simplified push pull amplifier and cavity systea as show in Figure 2A. Figure $2 B$ is the equivelent circuit, where. Ib is the beam current as show in Figure 1 , and $I_{1}$ and $I_{2}$ is the instantaneous current in each tube when Io $\neq^{2} 0$. With Ib not equal to rero, the instantaneous currexts through tube 1 (T1) and tube 2 (T2) are $I_{1}=I_{Q_{1}}-I_{p}$ and $I_{2}=I_{Q_{2}}+I_{p}$ respectively, were $I_{Q_{1}}$ and $I_{Q_{2}}$ are cutting off, $I_{Q_{1}}$ must be sufficiently high to keep $I_{1}$ from going negative. Allowing a 3 mp margin we get $I_{Q_{1}}=I_{1}+I_{P}=43$ mps. On the other hand, $I_{Q_{2}}$ can be ${ }_{3}$ amps and not have $I_{2}$ cut off. If the amplifier is to deliver $\pm 10 \mathrm{k} \nabla$ peak then the $D C$ voltage to the aplifier would be about $6 \mathrm{kV}$, resulting in total quiescent $D C$ porter input to the amplifier of $276 \mathrm{KW}$. Note that the push pull amplifier is being operated in an asymetrical fashion, othervise the DC power would have been much higher.

Let us now consider the simplified single ended aplifier and cavity system as shown in Figure $2 C$ and its equivalent circuit as show in Figure $2 \mathrm{D}$. To prevent the tube fron curting off, there are a number of factors that mut be considered for determining the quiescent cube current, $I_{Q}$; the beam current shape, the mplifier-cavity time constant, and the stable phase angle. The required value of $I_{Q}$, for the beam current hown in Fig. 1 , can have value betueen 1 to 8 mps. To develop a gap voltage of $\pm 10 \mathrm{kV}$, se need a DC voltage of $11 \mathrm{kV}$; therefore, the maximum quiescent $D C$ powe $=$ input to the single ended amplifier is $88 \mathrm{KW}$. The operating DC power input could be greater than $88 \mathrm{KW}$, but genera $11 \mathrm{y}$ it will be considerably less than the $276 \mathrm{kH}$ for a push pull amplifier.

From the above, it is obvious that the best theice from the point of $v$ iew of DC power requirements is the single-ended amplifier. Based on the 
above consideration of linenr operation it should be noted that the large difference in DC power requirements is due prianrily to the large ratio of $I_{p}$ to Ia; as this ratio approaches a value 2 , the $\mathrm{DC}$ power input for the push pull and single ended aplifier becone equal.

\section{The Single Ended Cathode Follower As An Arplifier}

Figure $3 A$ is a simplified diagran of aingleended cathode follower driving a resonant cavicy having a resonant frequency of $f_{O}$, and Figure $3 B$ is its equivalens circuit. It can be shown that at certain frequencies above $f_{0}$, where the carity has a negative reactance, the input impedance can have a negative real part, and, depending on the associated circuitry, mesult in an isstability of the anlifier. A nore detailed anslysis appears in the Reference.

To prevent oscillation the negative resistance mast be compenated for by adding a sufficiently large positive reaiscance in series with the input circuit. Figure $4 \mathrm{~A}$ show a cathode follower with its daping resistor $\mathbf{R g}$ and a resonant driver trensformer. As previously noted, the possibility of an instability occuring will be at a frequency above $f_{0}$; a simplified equivalent circuit at these frequencies is shown in Figure 4B, where $R d$ and $C^{\prime} d$ is the equivalent impedance of the driver tube and resonant coupling tranaformer, renpectively. The negative resistance, responsible for an instability, can be compensated for by the proper selection of $\mathbf{R g}$, Rd, and $c^{\prime} d$. This circuit does result in sall 11 reduction in the feedback ratio of the cathode follower and a corresponding sall increase in the output inpedance.

In the anplifier to be described that was constructed and tested, the grid to anode (ground) capacity, Cgp, was deliberately increased by adding an external capacitor so a to mintain a low output inpedance over a vide frequency range. By making CgP equal to the internal tube grid to cathode capacitance, Cgk, the feedback ratio was reduced to 0.5 , and the corresponding output inpedance of the cathode follower is $2 / \mathrm{G}$, where $G$ is the transconductance of the tube.

\section{Model of a Single-Inded Cathode Bollower Aplifier}

Shown in Figure 5 is a schesatic of a mel an plifier that was constructed and tested. A more detailed study of the circuit, as previously noted, appears in the Reference. Figure 6 is a photograph showing the ferrite cavity, output cathede follower, coupling traniforar and driver aplifier. The cavity and coupling transforer will be described in soeve future reports, but these itens follow sone conventional construction practices. The oals coment to be mde at this tive is that the coupling transformers should be designed with a high couplins coefficient $(k)$, otherwise both the output impedance and atability will be adversely affected. In our case $k$ was greatsr than 0.95 .

An interesting feature of the system is the ripple suppression cirevit; this will be discussed later on in this paper.

An important advantage of the circuit shown in Figure 5 is that the output of the cathode follorrer aplifier is connected directly to the sap of the cavity. In conventional grounded srid or grounded cachode anplifier coupling network is required to isolate the tube anode voltage from the cavity. This network adds an additional series impedance between the output of the aplifier and the cavity; which, obviously, increases the impedance as seen across the gap of the cavity.

\section{Keasurenents}

The rewonant frequency of the syatem is 235.4 $\mathrm{kHz}$ (the third harmonic of the CBA revolution frequeucy), and the wasurements were ande under the folloving operating conditions: anode voltage $11 \mathrm{kV}$, and various quiescent tube currents from 1 to 5 aps. Measurements wre ade both with and without a coaxial load resistor of 2000 ohns across the cavity sap. The dynaric output impedance (without any $\mathrm{DF}$ drive to the cathode follower) wa ceasured uning trunmission line (this asate vill be described in a future paper).

The agsten was found to be very stable under all operatins conditions of load and drive levels. The dynanic output impedance, as measured across the cap was 13 ohms or less up to a frequency of $10 \mathrm{mis}$.

It is important to point out the difference between the ceasured inpedance across the gap, 13 ohns, and the calculated cathode follower impedance of 7 ohns. This difference is due to the impedances transformations that are ascociated with the physical length of the tube and the connecting transeisuion line (which in approxintely 12 inches long) between the output of the tube and the cavity. Although it was not possible to rake a valid inpedance veasurewent directly at the output of the cathode follower, a cold (tube off) substitution whod was ned. It was found that a 10 ohn resiatance at the nube terminal wa trans formed, due to the connecting tranneission line, to 13 ohes at the gap of the carity. It is reasonable to assune that the physical length of the tube accounts for the calculated 7 ohn impadance of the tube being transformed to 10 ohes at the output ternina is of the tube. Clearly, this dictates that the tube should be wounted directly on the cavity.

\section{Ripple Suppression}

Due to the filant of the cathode follower beins directly heated from the AC line some $60 \mathrm{crcle}$ and higher harmic aplitude modulations wa observed. Prelininary tests of the dyaanic and passive ripple supression feedhack syaten ahowed great pronice. Our inat unentation, at this tim, did not perait very accurate asesurements, but it appeared that the total ripple was less than 17 at the full cutput voltage of $\pm 10 \mathrm{kV}$. By aking use of aimple passive 60 cycle hubbuckins signal, it was possible to reduce enentially all of the 60 ejcle components of modulation of the output signal. The design of the dynanic syaten is relatively simple since the bendwidth is only $60 \mathrm{kt}$ to $2 \mathrm{kBz}$ wich is far removed from the RF frequency of $235.4 \mathrm{kEx}$.

Some thought wan given to a DC filewent supply using either a tranaforwer and rectifier or a dyano cenerator, but neither of these sened to be a practical solution. Since the filment wings up and down with the peak R voltage, either of the above solutions would have reaulted in capacitive loading due to the large phyaical components that would have to be wunted direetly on the filenent.

\section{Future Hork}

A. was noted in this paper, the $D C$ power input efficiency of a single-ended or push pull plifier depends on the peak beas current. For the ail accelerating $\rightarrow$ lifier, were the peak current is 40 


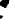
aps, the single-ended cathode follower is wout mandatory.

The stacking RF sybted for CBA, operating at a frequency of $4.45 \mathrm{mHz}$, has a much lower peak bean current. Preaently the design of a push puli cathode follower is being studied. It is felt that such a de sign has the advantage that it can be neutralized; consequently, the dependance of the driver impedance on the stability requirenents is greatly reduced. Concern for push push odes will have to be addressed, but the circuitry for push pirsh node suppression is independent of the push pull wode.

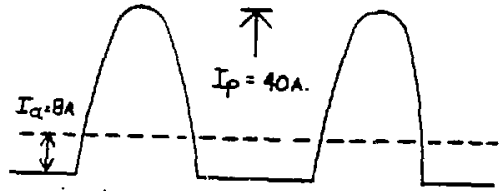

Fig.1 Typical Bean Current

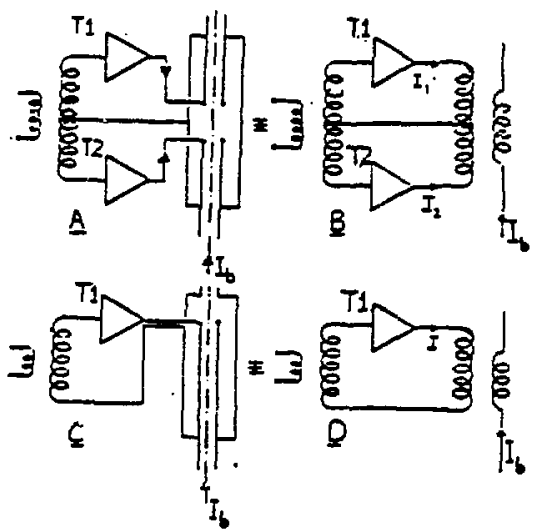

Fig. 2 Push-Pul1 And Single Ended Aplifiers

\section{Acknovi ed raent}

Wo would like to thank Lou Hazarakis, Frank Dicreecio and Phil Warner for constructins and teating the cathode follower aplifier.

\section{Reference}

A Linear and Non-Linear Analysis of High Power RF Anplifiers by M. Puglisi. 1983 Particle Accelerator Conference.

S. Giordano: Procesdings of the 1975 Isabelle Surmer Study, BNL 20550, pes. 500 to 514 .

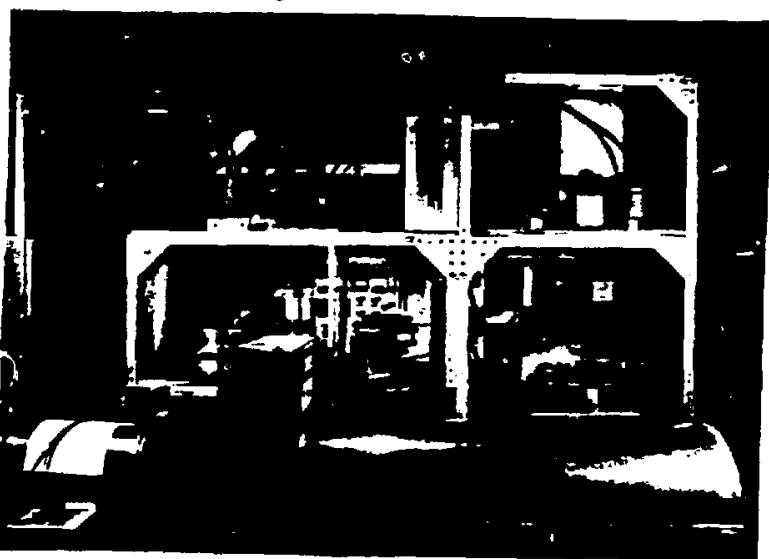

FiE. 6 Hodel Aplier And Cavity

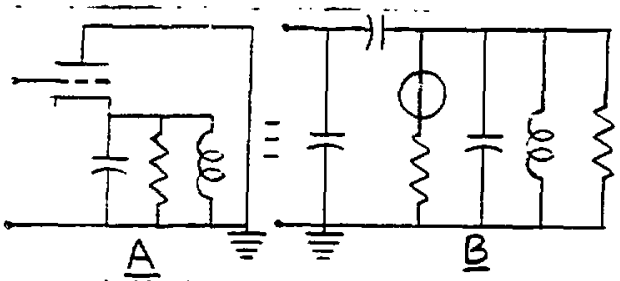

ig. 3 Cathode Follower Driving A Resonant Cavity
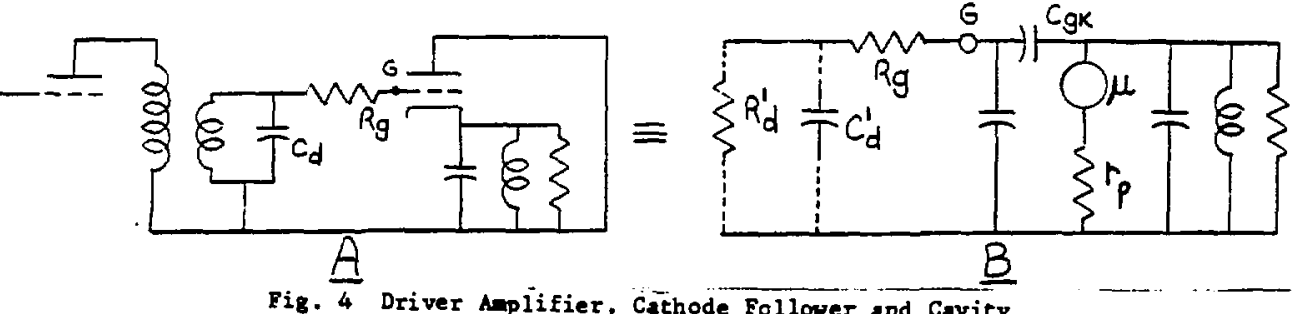

Fig. 4 Driver Aplifier, Cathode Follower and Cavity

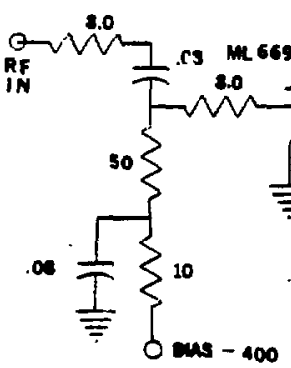

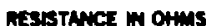
DePACTANCE IN $\mu \mathrm{FD}$

so

12

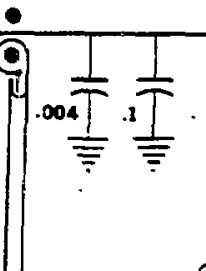

CAVITY

$T 1=$ FEnRITE CoUNLNG XFMR. T2 = FERRITE XFMR, WITH GIETTOSTTIC WITH

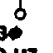
30 $.001 \frac{\sqrt{2}}{T_{0}}$

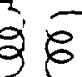

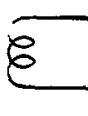

Fig. 5 Circuit Diagran of System
OVIunim RIPPLE

conthot.

PAC $\approx$ PASSIYE RIPPLE MHASE AnO Anitudue contro. 


\section{DISCLAIMER}

This report was prepared as an account of work sponsored by an agency of the United States Government. Neither the United States Government nor any agency thereof, nor any of their employees, makes any warranty, express or implied, or assumes any legal liability or responsibility for the accuracy, completeness, or usefulness of any information, apparatus, product, or process disclosed, or represents that its use would not infringe privately owned rights. Reference herein to any specific commercial product, process, or service by trade name, trademark, manufacturer, or otherwise does not necessarily constitute or imply its endorsement, recom. mendation, or favoring by the United States Government or any agency thereof. The views and opinions of authors expressed herein do not necessarily state or reflest those of the United States Government or any agency thereof. 